\title{
An investigation of Driver Attitudes Towards Road Safety in Oman
}

\author{
Eman Yousuf Al-Maimani \\ Hussin A.M. Yahia
}

\author{
Middle East College \\ Middle East College
}

\begin{abstract}
The Summary: Nowadays, road safety and associated behaviors received a lot of attention. Road Traffic Accident (RTA) is a combination of many factors comprising roads designs, vehicle and environmental conditions and human behavior. Human behavior is the most prevalent contributing factor for road traffic accidents. This study aims to identify accident risk factors associated with driving behaviors among the drivers in Oman and its risk perception. The study comprised the use of both qualitative and quantitative methods. The qualitative method included interviews with focus group from the Ministry of Transportation in Oman. The quantitative approach included analysis of road traffic accidents in Oman, followed by a survey questionnaire distributed to a random selection drivers in Oman. Both qualitative and quantitative data were analyzed using constant comparative and statistical techniques. The results showed that gender, age, and experience have significant influence on attitude towards the commission of traffic violations and risk behavior. The young and male drivers were found to be significantly more involved in road accidents, and the 26-33 years age group and those with minimal driving experience of 1-5 years constitute the risk-taking attitudes group. The results of this study will be of interest to the local community and transport planning in the Sultanate of Oman and it will help reduce traffic accidents and improve driver behavior.
\end{abstract}

\section{Introduction}

Traffic accidents prove to be a major problem worldwide. Around 1.3 million people die each year on the world's roads, and between 20 and 50 million suffer non-fatal injuries (.Ajzen, 22002) Over $90 \%$ of the world's fatalities on the roads occur in low-income and middle-income countries. The global losses due to road traffic injuries are estimated to be US\$ 518 billion and cost governments between $1 \%$ and $3 \%$ of their gross national product Oman has seen remarkable

Progress during the past four decades through the rapid economic growth, modernization, and the infrastructure development. This has reflected on the increase of automobile usage and car ownership. However, this development is accompanied by several problems such as traffic accidents According to the Global Road Safety Report 2013, Oman had registered 30.4 deaths per 100,000 people in 2010. (Ajzen, 2002).

Accidents are very complex events as these are combination of many factors such as highway geometry, driver behavior and human factors, speed limits, vehicle functions, and environmental conditions. Human error is found to be the most frequent contributing factor to road accidents. (Ajzen, 1991)

Many researchers studied the risky driving behavior (Hussin 2013). The age of the driver was considered as an important factor contributing to the occurrence of accidents, especially among the youth or younger generation (Sabey, 2003) Other studies like found that accident rates drop most dramatically during the first six months of driving.

Moreover, different previous studies showed that driving under alcohol or drug abuse affect the driver's ability to control the vehicle (Hussin 2013). 


\section{Journal of Student Research}

Fourth Middle East College Student Research Conference, Muscat, Sultanate of Oman

Accidents are very complex events as these are combination of many factors such as highway geometry, driver behavior and human factors, speed limits, vehicle functions, and environmental conditions. Human error is found to be the most frequent contributing factor to road accidents. Many researchers studied the risky driving behavior (WHO 2101) The age of the driver was considered as an important factor contributing to the occurrence of accidents, especially among the youth or younger generation (Sabey, 1980) Other studies like found that accident rates drop most dramatically during the first six months of driving. Moreover, different previous studies showed that driving under alcohol or drug abuse affect the driver's ability to control the vehicle ( Eiksund 2009).

Since the human error is the most contributing factor in road accident, in which driver behavior is a primary determinant. Therefore, several studies have been conducted to associate driver attitudes with various risky driving behaviors [12, 13].

Wilde (2001) pointed out that the Factors affecting the level of risk could be attributed to social, cultural, or psychological reasons. The amount of level risk that driver can take depends on the accepted benefits of risky behavior, e.g. Increase the speed to save time or the use of uncomfortable safety packs affects driver behavior. The study showed that drivers who have a modern car and equipped with airbags drive more aggressively, which increases the risk of death.

They found that excitement-seeking, altruism, aversion to risk taking, and likelihood of having an accident were the main causes of speeding behavior among the young drivers (Hussin,2013) Chang (2011) using a questionnaire, explored the crash risk and driving behaviors of ALLR (Administrative Lifetime Driver's License Revocation) drivers in Taiwan, China. The results showed that the crash risk of offenders significantly correlated with their personal characteristics, penalty status, annual distance driven, and needs for driving. The drivers' fatigue or tiredness is one of the four causes for accidents or injuries (Shinar, 2001)100,000 motor vehicle crashes are the direct result of driver fatigue each year in the US. Additionally, more than one-third of drivers in USA (about 103 million people), have actually fallen asleep at the wheel, (Iversen, 2004) Gulliver \& Begg, 2004 study the relationship between early driving (5-18 years) experiences and behaviors and perceptions of safe driving. They demonstrated relationships between early experiences of aggressive behaviors and accident involvement.

A study by Hussin et al. 2017 developed a traffic safety index in a framework investigated the relationship between antecedents and consequences of car driver behavior towards road traffic accidents involvement using a structural equation model (SEM). The results showed that Speed is one of the most significant factors in road accidents and it is affected by factors which include driver's age, gender and attitude. Therefore, different drivers choose different speeds for the same conditions (Hussin 2016)

According to official reports issued in Oman, the first cause of death, hospital patients and serious injuries is the result of traffic accidents. Ministry of Health, 2009 (Hussin, 2015).

The accident causes in Oman are speed, neglect, fatigue, overtaking, weather condition, safety distance, vehicle defect, road defect, and it should be noted that more than $90 \%$ of the road accidents are due to driver's behavior [17].

Enhancing road safety is one of the remedial measures introduced and is crucial because of the need for proper enforcement, education, and engineering, (Schechtman, 1999) These measures have already been applied in a number of developed countries and potentially yielded positive results in terms of changing the attitudes and behavior of drivers. However, the developing countries are taking advantage of the counter measures on the basis of experience in developed countries, still the differences in behavioral, cultural, and economic aspects between them must be considered. 
The main aim of this paper is to study accident risk factors associated to driving behaviors among the drivers in Oman and its risk perception and the risky driving behavior through three main objectives:

- To analyze trend of road traffic accident in Oman during the period 2010 to 2016,

- To identify the most major contributing factors to traffic accident, and

- To study the risk factors associated to driving behaviors among the drivers in Oman in Muscat, Oman.

In this study, statistical data obtained from different government authorities is used. After analyzing the data, safety measures initiated from the government authorities was discussed and more safety points were proposed to reduce road traffic accidents and improving driver behavior.

\section{Research Methodology}

For a better understanding of research problems, a combination of qualitative and quantitative approaches were used. The qualitative method includes interviews with a focus group from the Ministry of Transportation in Oman. The quantitative approach includes analysis of road traffic accidents in Oman followed by a survey questionnaire carried out among drivers in Oman. Both qualitative and quantitative data were analyzed using constant comparative and statistical techniques with the Statistical Package for the Social Sciences (SPSS).

The study sample comprised 120 drivers. 90 drivers (75\%) ultimately completed the administered questionnaire and were considered to constitute the final sample in the selected areas (Al Quram, Mattrah) these areas were chosen due to traffic congestion.

The pilot study were conducted in selected areas to ensure that validity and reliability of the scales are acceptable before the actual data collection is done. Data was collected from questionnaires of the pilot study and program SPSS used to calculate the Cronbach Alphas. The data was accepted by 0.97 Cronbach's Alpha.

\section{ROAD SAFETY IN OMAN}

The Sultanate of Oman is located on the south-eastern side of the Arabian Peninsula, and the southwest of the Asian continent, bordered on the north-east by the Sea of Oman, the south-east by the Indian Ocean, the Kingdom of Saudi Arabia lies in the west of the Sultanate in addition to the United Arab Emirates, Yemen lies south, bordered by the Strait of Hormuz from the north, while the Arabian Sea is bounded from the east. The country also contains Madha, an enclave enclosed by the United Arab Emirates, and Musandam,

To provide an adequate background on the subject of road safety in Oman, the geographical features of the country must be considered. The Sultanate of Oman is administratively divided into 11 governorates: These governorates consist of a total of 61 states, each governorate has one or more regional centers and the total number of regional centers in the Sultanate is 12 .

The statistics confirmed that Muscat governorate is the highest in the population density by about 365 inhabitants / per square as shown in figure 1.1 followed by the governorates of North and South Batinah and South East Governorate by about 94, 78 and 26 inhabitants / per square, respectively. The governorates of Dhofar and Central occupy about 59\% of the Sultanate's area, while about $11 \%$ of the population of the Sultanate and the population density of about 5 people / per square 


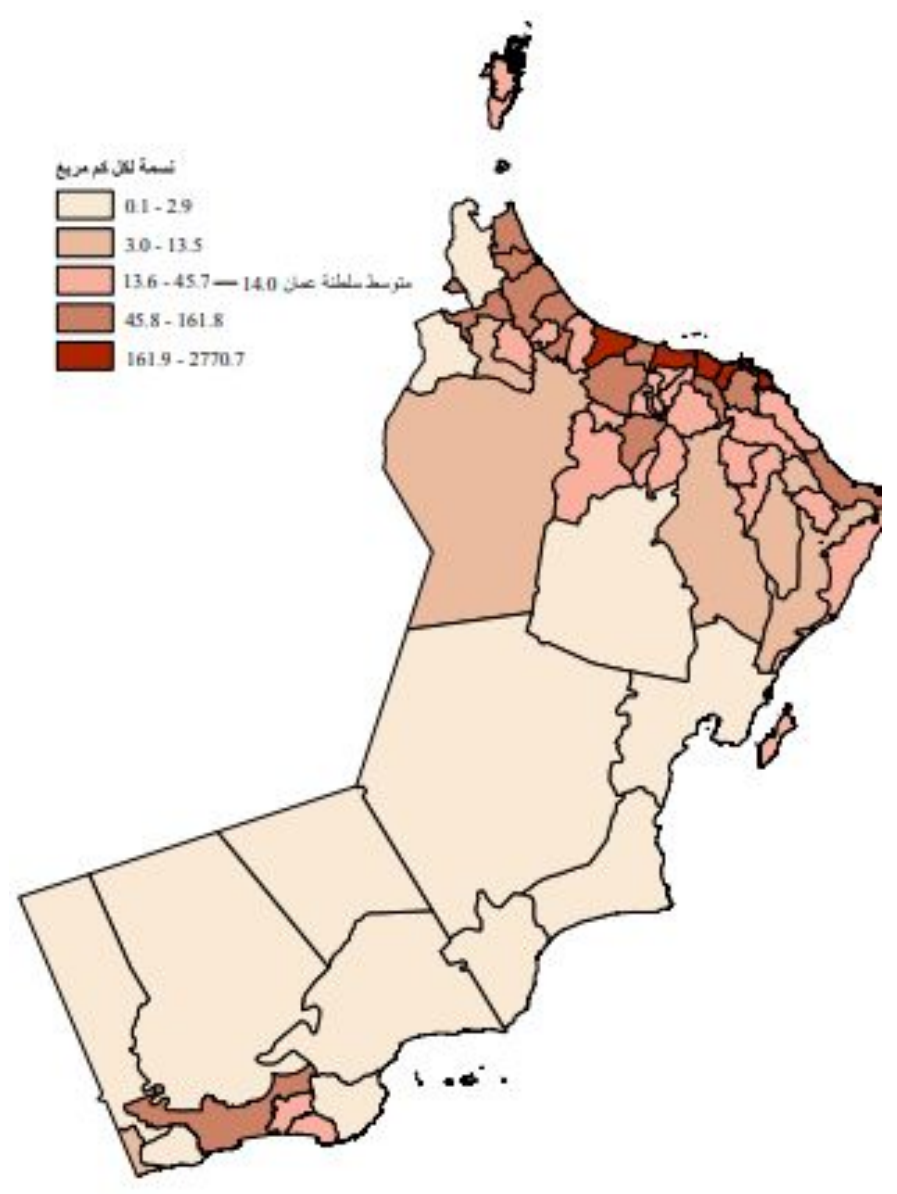

Figure 1. Population density

The government provides convenient transportation between cities, but most citizens prefer to travel by their own car for long distance. Thus, road traffic between cities is massive. Considering that the distance between some cities is more than $1000 \mathrm{~km}$.

\section{Qualitative Approach Analysis}

In this study, in-depth interviews and focus groups were used to obtain information about knowledge, behaviour, and attitude of drivers towards road accidents and the main causes of traffic accidents. This method enabled the researcher to find out more details about the topics and issues concerned and to generate more definite answers to the interview questions.

Interviews were conducted with the focus group from the Ministry of Transportation in Oman. The interviews were to find out their point of view from daily experiences, from different ranks about the cases of traffic accidents, limitation of traffic safety in Oman.

The questions were prepared to focus on the research problem and objectives. The questions included following:

- Do you think Traffic accidents and car driver behaviour are a problem need to study in Muscat?

- What factors affect car driver behaviour?

This questions focuses on two aspects: road accidents problem and who are responsible for those 


\section{Journal of Student Research}

accidents. The opinions presented from experts and key findings from their answers were as following;

Most of the respondents confirmed that, road traffic accidents are a major problem in Oman and especially for young people. According to data from the National Center for Statistics and Information. Compared to 6,279 accidents in 2015, the year 2016 witnessed 4,219 traffic accidents, reflecting a drop of 32.8 per cent. However, compared to 675 people who lost their life in road accidents in 2015, 692 died in such incidents in 2016. However, the number of those injured fell by 19.2 per cent, from 3,624 in 2015 to 2,929 in 2016 . The main reason for traffic accidents as perceived by respondents has been illustrated as follows.

Most of the participants confirmed that the behavior of the driver on the road is one of the most important causes of traffic accidents in Muscat and they have listed the most erroneous behaviour of the drivers such as: wrong overtaking, passing allocated speed, driving in the opposite direction and failure to comply with the priorities of traffic, as well as the respondents also highlighted the impact of weather conditions, especially in desert areas during the summer

Most of the respondents confirmed that behaviour of drivers is the cause to many accidents; and they have listed the most erroneous behaviour of the drivers such as: by passing allocated speed, wrong overtaking, and failure to comply with the priorities of traffic, in addition to driving in the opposite direction, and not taking into account the ethics of traffic when dealing with passengers and pedestrians, as well as the respondents pointed out the role of vehicles in causing traffic accidents, they claimed that, the vehicle validity is one of the key elements to ensure traffic safety, as well as the respondents highlighted the weather conditions a high impact factor for accidents in roads, especially in highways, sudden changes in weather such as, high temperatures in summer, rain or severe storms affect the behaviour of the drivers and makes them to lose control of driving. Regarding to recommendations and opinions they stressed the government should focus on driving schools especially for young people at early age above 18, In addition, road safety campaigns and publicity play an important role in raising driver awareness.

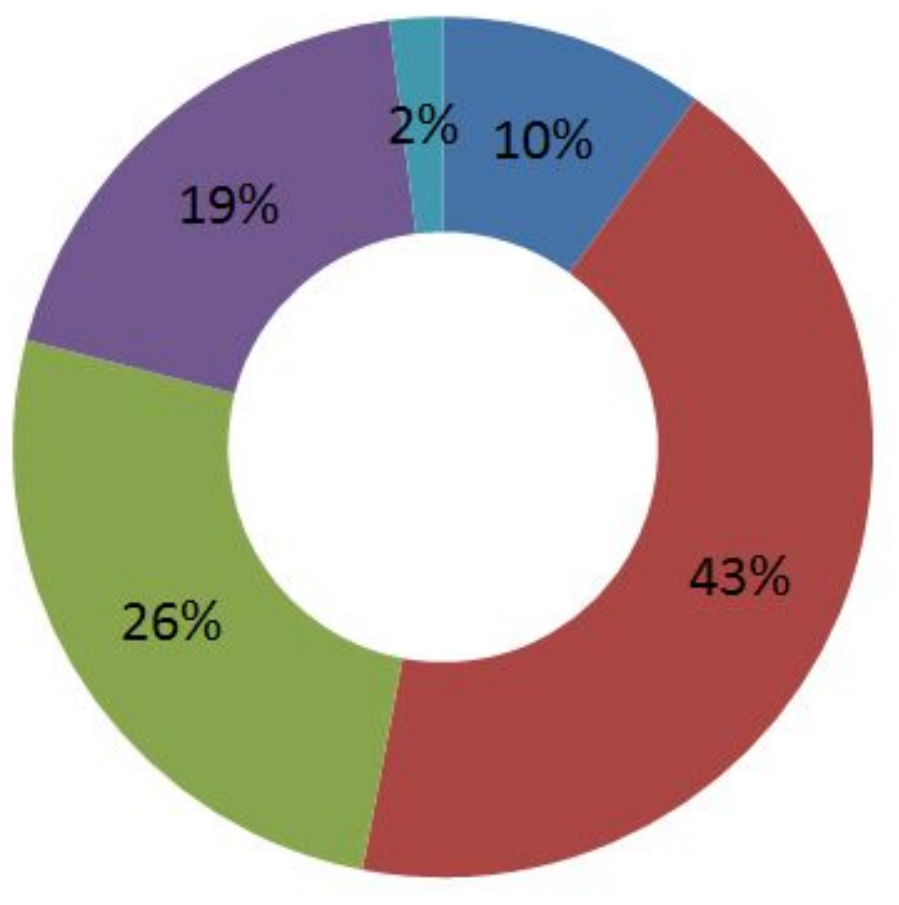

Vehicles

Driver's

Infrastructure for roads

Environment factors Others

Figure 2. Causes of traffic accidents

The summary of interventions as perceived by respondents has been tabulated below: 
Journal of Student Research

Fourth Middle East College Student Research Conference, Muscat, Sultanate of Oman

\begin{tabular}{|c|c|c|c|c|c|c|}
\hline \multirow[t]{2}{*}{ Interventions } & \multicolumn{6}{|c|}{ Respondents } \\
\hline & 1 & 2 & 3 & 4 & 5 & 6 \\
\hline Driving schools & & $\overline{\sqrt{ }}$ & $\sqrt{ }$ & $\sqrt{ }$ & & \\
\hline $\begin{array}{l}\text { Campaigns and } \\
\text { publicity }\end{array}$ & $\sqrt{ }$ & $\overline{\sqrt{ }}$ & & $\sqrt{ }$ & $\sqrt{ }$ & $\sqrt{ }$ \\
\hline Cars parking & & $\sqrt{ }$ & & & $\sqrt{ }$ & \\
\hline $\begin{array}{l}\text { places for } \\
\text { walkers }\end{array}$ & $\sqrt{ }$ & & & & $\sqrt{ }$ & \\
\hline $\begin{array}{l}\text { Improvement of } \\
\text { the road } \\
\text { network }\end{array}$ & & $\sqrt{ }$ & & & $\sqrt{ }$ & $\sqrt{ }$ \\
\hline $\begin{array}{l}\text { Law imposes on } \\
\text { violators }\end{array}$ & $\sqrt{ }$ & & $\sqrt{ }$ & $\sqrt{ }$ & & $\sqrt{ }$ \\
\hline \begin{tabular}{|l} 
Encourage \\
people to use \\
public transport
\end{tabular} & & $\sqrt{ }$ & $\sqrt{ }$ & & $\sqrt{ }$ & $\sqrt{ }$ \\
\hline
\end{tabular}

Table 1. The most important recommendations and opinions

The key findings from their answers were as following.

- The traffic accidents have a significant impact on traffic and have caused disruption of public interests. It is considered as one of the main problems that causes death,

- Poor maintenance and non-compliance with traffic safety measures of vehicles is one of the most important factors that affect car driver behaviors.

- Some common mistakes such as road drilling and erosion of asphalt.

- Conditions such as rain and road defects have an impact on the road accidents.

- Geometric planning errors and traffic congestion.

- The main cause of traffic accidents is the driver's behavior in terms of aggressive behavior, excessive speed, using mobile phones, dangerous overtaking and not maintaining a safe distance between vehicles.

- Some of the motorists do not follow traffic rules

- Finally to improve the traffic safety, they recommended to Increase awareness, outreach programs, and the dissemination of a conscious traffic culture and find alternative modes of transportation such as trains, and buses.

\section{Analysis of traffic accident trend in Oman}

The data of accidents in Oman was collected for 7 years from ROP during 2010 to 2016. The data include the number of accidents, injuries and deaths in Oman and its causes (ROP 2016). It is observed that 2012 was the highest in total number of accident, injuries, and fatalities accident. 2015 was the lowest in number of fatalities accident and 2016 was the lowest in general which reflect that there is a reduction in the number of accidents. Figure 1 shows the trend of total accidents, Fatalities and injuries between 2010 and 2016.

Road accidents are the first and foremost cause of deaths, hospitalizations, and serious injuries (Hussin, 2012). According to official reports issued by ROP Oman, the main causes of accidents in Oman are speed, neglect, fatigue, overtaking, sudden stopping, improper act, drunk driving, 
weather condition, safety distance, vehicle defect, and road defect.

It found that the speed is the first cause for accidents followed by neglect, fatigue, overtaking, safety distance, improper act which are related to driver behavior (Hussin 2017). Figure 2 shows the cause of road accident. Fernandes et al 2010 found that low risk perception is associated with higher rates of speed, and therefore increase the chances road accidents (Hussin, 2017)].

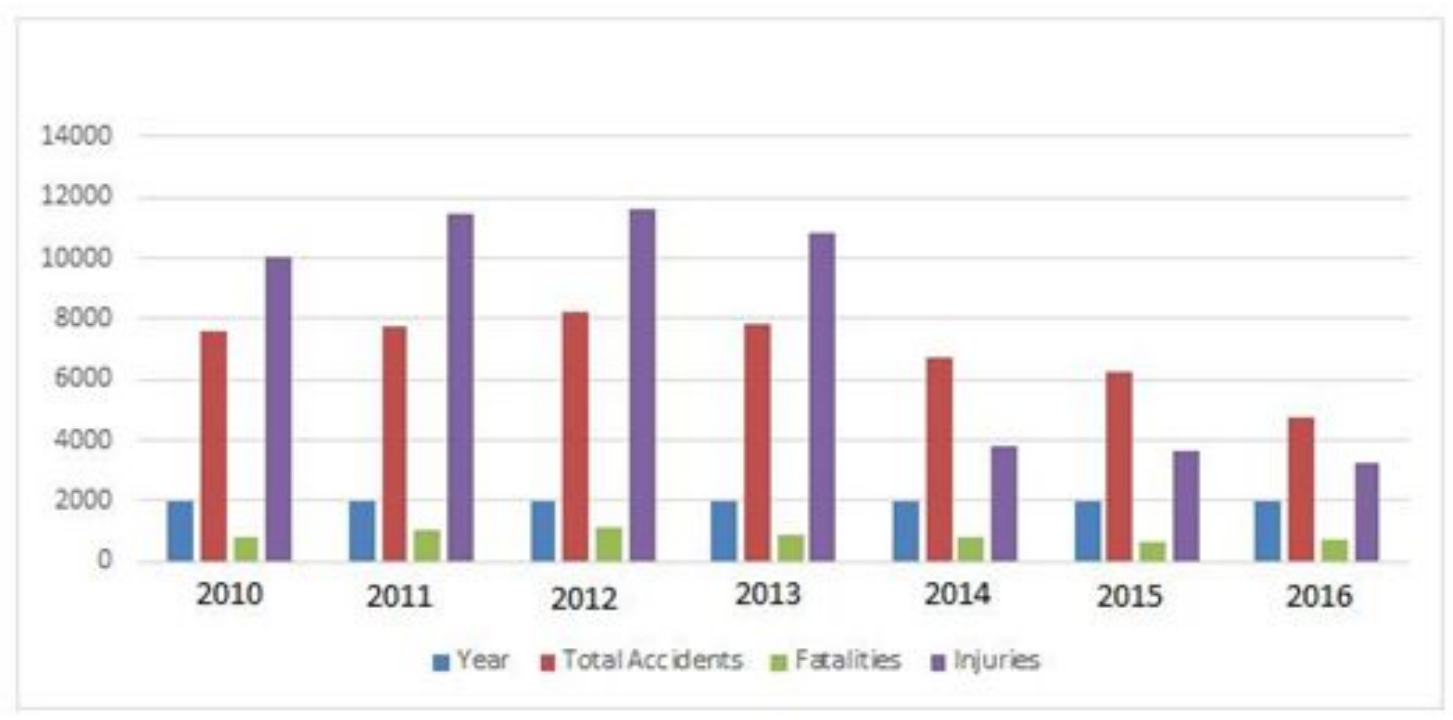

Figure 3. Road Traffic Accidents in Oman

\section{Quantities Approach Analysis}

The analysis was conducted to investigate accident risk factors associated to driving behaviors among the drivers in Oman and its risk perception, risk-taking attitudes, and the risky driving behavior. The factors that were expected to have an impact on the behavior of car drivers towards road traffic accidents (RTA) involvement in Oman were classified into two groups:

- The first group includes factors related to demographic characteristics of the driver such as: age, gender, level of education, occupation, nationality and experience in driving.

- The second group includes the factors related to behavior of car drivers.

Survey questions targeted drivers from different areas, background and demographic characteristics in Muscat as shown in table 2. Out of the 90 questionnaires, which were distributed, 72 questionnaires were returned. Respondents consisted of $56.7 \%$ male and $43.3 \%$ female, $85.6 \%$ are Omani and $14.4 \%$ are non-Omani. Based on the age profile of respondents, it was found that respondents were mainly (42.2\%) in the age group of 26-33 years old followed by 34- 41 years old $(26.7 \%)$ and $18-25 y e a r s$ old $(24.4 \%)$. About $73.3 \%$ of the respondents had University level education, and $21.1 \%$ of them Secondary education. $8.9 \%$ of respondents were business men, while $4.4 \%$ of respondents were already retired. 68 respondents $(32.2 \%)$ worked in the government sector, while 15 persons (16.7\%) were still studying. An investigation of the marriage status points to the fact that the proportion of single and married respondents was $35.6 \%$ and $57.8 \%$ respectively. $28.0 \%$ of respondents were the most experienced ( $>12$ years); respondents with 6-12 years and $1-5$ years of experience were $31.4 \%$ and $40.6 \%$, respectively. 


\section{Journal of Student Research}

Fourth Middle East College Student Research Conference, Muscat, Sultanate of Oman

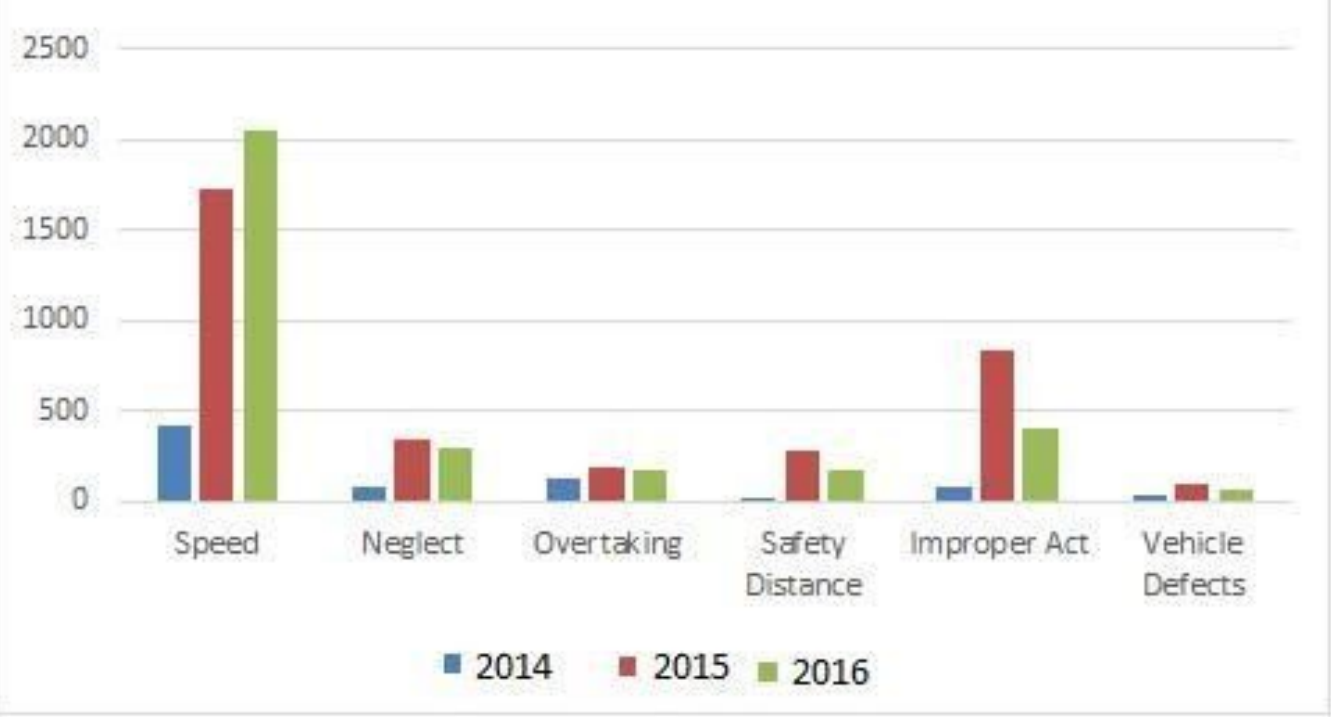

Figure 4. Causes of traffic accidents

\begin{tabular}{|c|c|c|c|}
\hline \multirow[t]{2}{*}{ Variables } & \multirow[t]{2}{*}{ Category } & \multicolumn{2}{|c|}{ Results } \\
\hline & & $\mathrm{F}$ & $\%$ \\
\hline \multirow[t]{2}{*}{ Gender } & Male & 51 & 56.7 \\
\hline & Female & 39 & 43.3 \\
\hline \multirow[t]{3}{*}{ Nationality } & Omani & 77 & 85.5 \\
\hline & Non-Omani & 13 & 14.4 \\
\hline & 18-25years old & 22 & 24.4 \\
\hline \multirow[t]{4}{*}{ Age Group } & 26-33 years old & 38 & 42.2 \\
\hline & 34- 41 years old & 24 & 26.7 \\
\hline & $>=42$ years old & 6 & 6.7 \\
\hline & None educated & 1 & 1.1 \\
\hline \multirow[t]{4}{*}{ Education } & Intermediate & 4 & 4.4 \\
\hline & Secondary & 19 & 21.1 \\
\hline & University level & 66 & 73.3 \\
\hline & Government employees & 29 & 32.2 \\
\hline \multirow[t]{3}{*}{ Occupation } & Business men & 8 & 8.9 \\
\hline & Retired person & 4 & 4.4 \\
\hline & Students & 15 & 16.7 \\
\hline \multirow[t]{2}{*}{ Material Status } & Single & 32 & 35.6 \\
\hline & Married & 52 & 57.8 \\
\hline Experience in & $1-5$ years & 28 & 31.1 \\
\hline \multirow[t]{2}{*}{ Driving } & $6-12$ years & 43 & 47.8 \\
\hline & $>12$ years & 19 & 21.1 \\
\hline
\end{tabular}

Table 2. shows the Respondents profile

\section{Descriptive Analysis}

In order to consider every concept or construct of the antecedents, mediating and consequences of car driver attitude towards RTA involvement, the scores of standard deviation and the mean were recorded. In this questionnaire, the participants were asked to rate their perception about the 75 


\section{Journal of Student Research}

items provided on a five-point Likert coded and decoded scale. (1) Strongly Agree, (2) Agree ; (3) Neutral; (4) Disagree, and (5) Strongly Disagree.

The questionnaire survey consisted of 17 different categories of driver behavior that included their opinion on the following statement (1) I service my car every six months, (2) I check my car before driving, (3) I observe traffic regulation, (4) Prior to driving, I fasten my seat belt, (5) I drive my car above the posted speed limit, (6) I use signals when changing lanes, (7) I disregard weather or traffic condition while driving, (8) I respect the pedestrian and adhere to the right while driving, (9) I sometimes fail to stop or give way at a stop sign, (10) I eat, drink or smoke while driving, (11) I use cassette / radio or telephone while driving, (12) I use headlights while driving, (13) I make use of front and side mirrors, (14) I use a mobile phone while driving, (15) I use special seat for children in my car, (16) I continue driving for long hours, and (17) I drive when I am under psychological stress. Responses to the questionnaire are made on a five-point scale that include strongly disagree, disagree, somewhat agree, agree, and strongly agree. Table 3 . Shows the participant respond to driving behaviors among the drivers in Oman. The feedback from respondents who sometimes fail to stop or give way in the stop sign and its impact on traffic security. Participants were asked to check the stop sign. In this question, $10.0 \%$ of respondents strongly disagreed, $32.2 \%$ disagreed, $40.0 \%$ were neutral, $14.4 \%$ agreed, and $3.3 \%$ strongly agreed. (Table 4.10) that the average scores were 3.31 and Std.Dev 0.956.

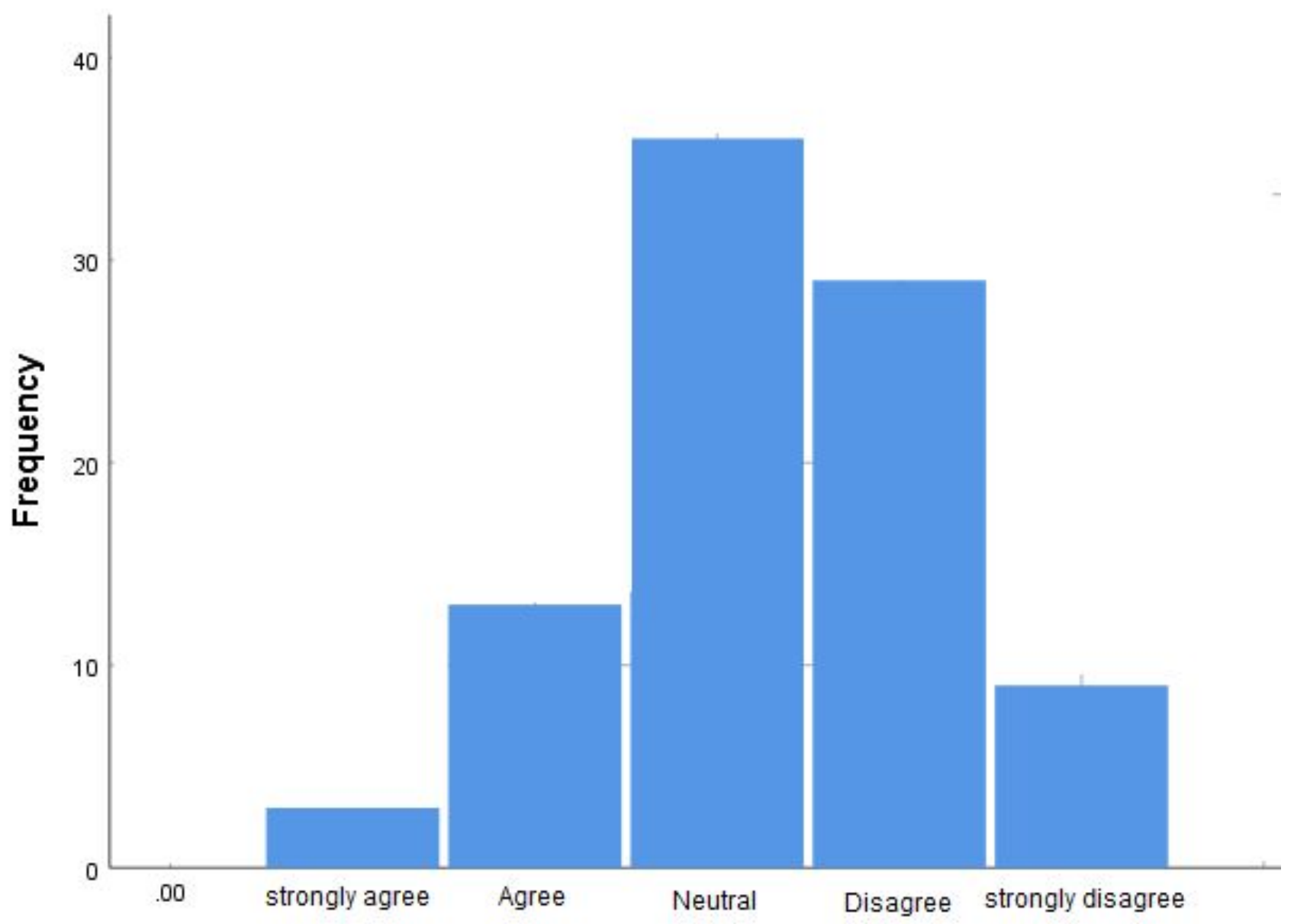

Figure 5. Fig Sometimes fail to stop or give way at a stop sign

The respondents' views on using the mobile phone during the driving were $20.0 \%$ of respondents said strongly disagreed, $14.4 \%$ disagreed, $33.3 \%$ were neutral, $24.4 \%$ agreed, and $7.8 \%$ strongly agreed. 


\section{Journal of Student Research}

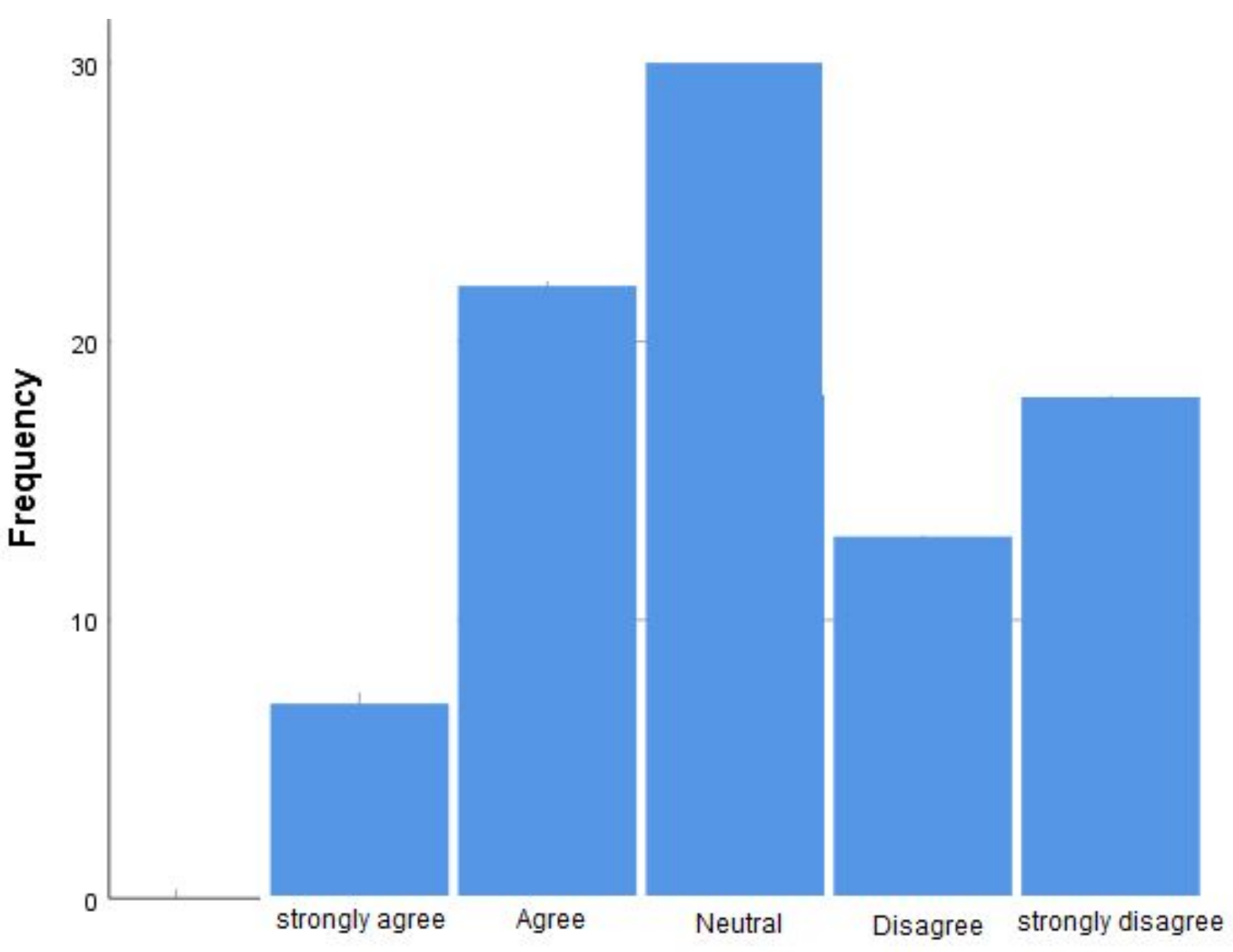

Figure 6. using the mobile phone during the driving

\section{The relationship between the demographic characteristics and driver behavior}

In second part of analysis the relationship between the demographic characteristics and driver behavior were analyzed. Gender and risk factors associated to driving behaviors. In gender comparison and the verification of the car before driving, it is found as shown in figure 3 the male are more likely to check their vehicle before driving.

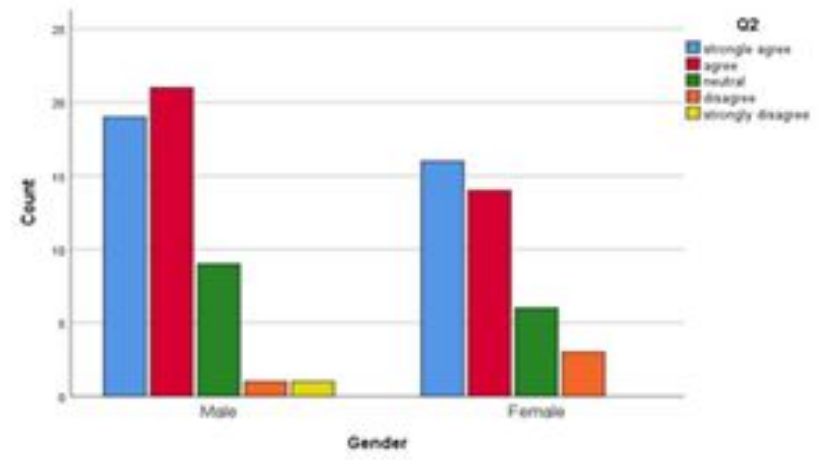

Figure 7. Relation between Gender and Check your car before driving.

The relationship between the gender and using the mobile phone as shown in figure 6 , it is found 


\section{Journal of Student Research}

that men are more likely to use their mobile phones while driving than women, and the proportion of men is equal. While the relationship between age and the use of mobile phones during driving, shows that the age group 26-33 is the most neutral of the other groups, namely youth. The 18-25 group is the most consistent of the other groups.

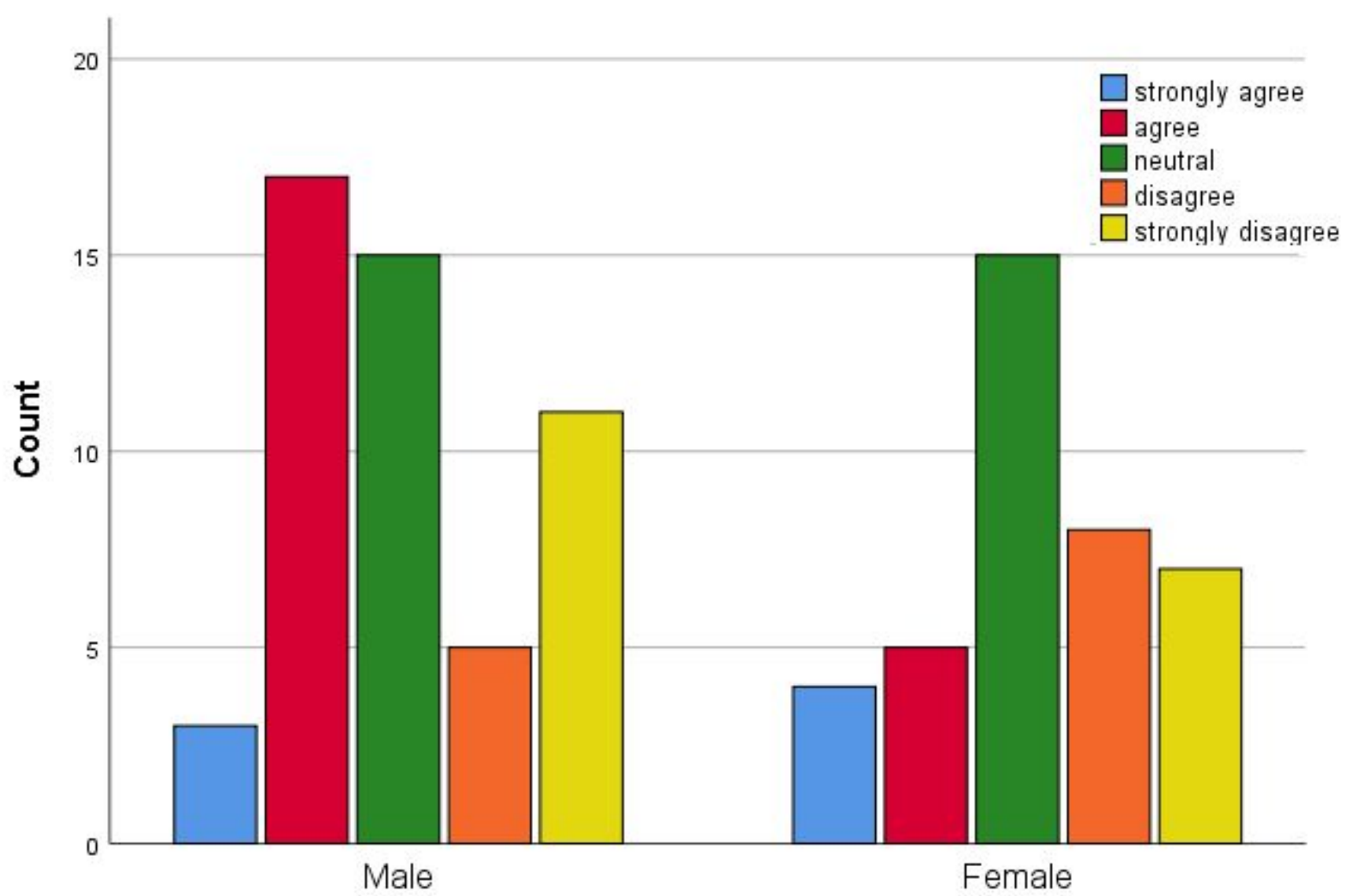

Gender

Figure 8. using the mobile phone

\section{Conclusion and Summary}

The result of accidents is a mixture of several factors that include human factor, environmental, and road design. More than $90 \%$ of road accidents is due to human factors. The objectives of this study included an analysis of road traffic accidents in Muscat 2010-2016, a study of road accident impacts and consequences (RTA) in Muscat, Sultanate of Oman, and providing recommendations to reduce road traffic accidents and improve driver behavior. The accident analysis showed that the accident trend decreases gradually, as Oman in 2012 ranked the highest in road accidents however in 2016 it is reduced to the lowest. This is due to the efforts exerted by Oman Police to reduce traffic accidents

Generally, it is found that men check their cars before driving, but they are more likely to use mobile phones while driving than woman. However both men and woman totally disagree to drive car above speed limit. The gender ratio is higher in case of male than that of female. Other findings are grouped 26-33 agree to check their cars before driving and the same age group remains neutral regarding driving the car above speed limit. The driving experience plays an important role when it comes to driving 1-5 years, this group uses mobile phone while driving and 6012 years driving tend to drive car above the speed limit. Recommendations to reduce accidents and improve traffic safety may include; 


\section{Governmental response}

- Enforcing regulations and laws especially in using safety belts, speeding, and using the phone while driving.

- The safety unit must be carried out on road safety procedures and road safety unit in terms of information and drive by radio and television. A campaign must be conducted in schools for students.

- The government and ministries are responsible for repairing road signs each time, if necessary, it should be replaced, especially in highly populated areas and in small towns.

- Establish a continuous monitoring unit (vehicle inspection unit. Every year, at least once all the vehicles should be checked, and certified after being subject to inspection. For example, safety standards, such as lights, safety belts, appropriate brakes, good tires and indicators, should be met.

\section{Personal response}

- Attention and compliance with the rules related to traffic safety.

- One shouldn't drive the car while feeling tired or drowsy.

- Regular inspection and service of the vehicles

\section{Acknowledgements}

The research was conducted in collaboration with the Department of Civil Engineering, Middle East College/ Knowledge Oasis Muscat, Oman

\section{References}

Ajzen, I. (2002). Perceived behavioural control, self-efficacy, locus of control, and the theory of planned behavior. Journal of Applied Social Psychology, 32, 665-683.

Ajzen, I., 1991. The theory of planned behaviour. Organizational Behavior and Human Decision Processes 50, 179-211.

Darby, P., Murray, W., \& Raeside, R. (2009). Applying online fleet driver assessment to help identify, target and reduce occupational road safety risks. Safety Science, 47(3), 436-442.

Hussein A.M Yahia \& Amiruddin Ismail 2013. Causes and effects of road traffic accidents in Tripoli - Libya. Proceeding the 6th Civil Engineering Conference in Asia Region: Embracing the Future through Sustainability. Jakarta, Indonesia ISBN 978-602-8605-08-

Hussin, A.M.Y. and I. Amiruddin, 2011. Traffic accidents in Libya. Proceeding of the International Conference on Traffic Longistic Engineering. Chennai, India.

Hussin A.M. Yahia and Amiruddin Ismail, 2014. Knowledge of Traffic Laws and Drivers Behavior on the Roads of Tripoli City, Libya. Research Journal of Applied Sciences, Engineering and Technology 7(10): 2040-2045, 2014 ISSN: 2040-7459; e-ISSN: 2040-7467.

Hussin A.M Yahia, 2016. Antecedents and Consequences of Car Driver Behaviours towards RTA 


\section{Journal of Student Research}

Fourth Middle East College Student Research Conference, Muscat, Sultanate of Oman

Involvement using Structural Equation Models (SEM), International Journal of Transportation Systems.

Hussin A.M Yahia 2011, Hussin AM Yahia, Amiruddin Ismail, Traffic Accidents Analysis in Libya, Sustainable Building and Infrastructure Systems: Our Future Today.

WHO (World Health Organization), 2010. Global status report on road safety: Time for action. World Health Organization, Geneva.

Syed and Shamsul (2003). Study of heavy vehicles driver behavior in road accidents of Bangladesh, 26th Australian Transport Research Forum. New Zealand 1-3 October 2003.

Sabey, B. \& G. Staughton 1975. Interacting Roles of Road Environment Vehicle and Road User in Accidents. CESTE I MOSTOVI.

Sabey, B. E. \& H. Taylor. 1980. The known risks we run: the highway Ed.: Springer.

Treat, J. R. 1980. A study of precrash factors involved in traffic accidents. HSRI Research Review.

Varhelyi, A. 1997. Dynamic speed adaptation in adverse conditions. Proceedings, 4th World Congress on Intelligent Transport Systems. pp. 21-24.

Evans, L. 1996. The dominant role of driver behavior in traffic safety. American Journal of Public Health 86(6): 784-786.

Eiksund, S., 2009. A geographical perspective on driving attitudes and behaviour among young adults in urban and rural Norway. Safety Sci., 47(4): 529-536.

Farah, H., 2011. Age and gender differences in overtaking manoeuvres on two-lane rural highways. Transp. Res. Record, 2248: 30-37.

Iversen, H.H. and T. Rundmo, 2004. Attitudes towards traffic safety, driving behaviour and accident involvement among the Norwegian public. Ergonomics, 47(5): 555-572.

Koushki, P.A., S. Yaseen and O. Al-Saleh, 1998. Road traffic violations and safety belt use in Kuwait: study of driver behavior in motion. Transp. Res. Record, 1640: 17-23.

Schechtman, E., D. Shinar and R. Compton, 1999. The relationship between drinking habits and safe driving behaviors. Transp. Res. Record, 2(1): 15-26.

Shinar, D., E. Schechtman and R. Compton, 2001 Self reports of safe driving behaviors in relation to sex, age, education and income in the US adult driving population. Accident Anal. Prev., 33(1): 373-385. 